\title{
O SERTÃO DILACERADO: OUTRAS HISTÓRIAS DE DEUS E O DIABO NA TERRA DO SOL
}

\author{
Pedro Paulo Gomes Pereira
}

Cada sociedade elege um núcleo de preocupações ao qual confere centralidade. Em torno desse núcleo se elaboram perguntas e temas constantes, e sofisticados aparatos conceituais que se destinam tanto a amenizar os dilemas como a ampliar os questionamentos - as prioridades se estendendo, inclusive, às formas e aos meios pelos quais essas perguntas são enunciadas e reiteradas ${ }^{1}$.

Este ensaio buscará se aproximar de um desses núcleos; aproximação, evidentemente, parcial e com objetivos modestos e delimitados. Trata-se de uma geografia imaginativa que, no Brasil, desenhou uma categoria de espaço, o sertão, como uma das formas principais de falar e definir a nação, e que escolheu o cinema como um meio de expressão apropriado. A tentativa será a de compreender como uma narrativa de

\footnotetext{
${ }^{1}$ Utilizo, aqui, termos de Rita Laura Segato (1995) e Eduardo Viveiros de Castro (2002a), que apontam tanto para a existência desse núcleo de preocupações e indagações, quanto indicam a necessidade de identificar as perguntas de nossos interlocutores, em vez de buscar respostas para as nossas próprias. Estou ciente das limitações teóricas do conceito de "sociedade" e só o utilizo aqui de forma bem geral, sem prejuízo para a análise desenvolvida. Sobre esse assunto, ver Strathern (1996) e Viveiros de Castro (2002b).
} 
importância ímpar na filmografia nacional, Deus e o Diabo na terra do sol, de Glauber Rocha, construiu o sertão, quais as imagens e as figuras utilizadas, e como esse sertão delineia e projeta o Brasil ${ }^{2}$. Nas páginas que se seguem - além de abordar, na parte inicial do ensaio, as relações entre tropo, espaço e sertão - argumentarei que Glauber Rocha constrói poderosas alegorias da nação. Em Deus e o Diabo, o sertão se constitui, simultaneamente, naquilo que identifica o Brasil diante de seus outros, e num outro da nação. As alegorias do filme, elaboradas no epicentro dessas relações de alteridade, se distanciam das alegorias pedagógicas e previsíveis, e nos apresentam um sertão dilacerado, inscrevendo na história da nação outros momentos, outras histórias em que personagens ambíguos, à margem, inseguros e em constante travessia assinalam a violência contida na idéia de um tempo no qual o sertão ora deveria ser vencido pela civilização, ora seria petrificado como arcaico idealizado.

\section{Aproximações: espaço, tropo, sertão}

Num de seus textos mais instigantes, Michel de Certeau (1996, p. 199) nos lembra que, na Atenas contemporânea, o transporte coletivo é denominado de metaphorai; os gregos utilizam metáforas para se locomover - ato de nomear, que denota a íntima vinculação entre narrativa e espaço. A locomoção, a transposição no espaço, é metafórica, já que a metáfora é justamente a manifestação das maneiras de se passar a outro, de se transfigurar. As narrativas possuem, assim, valor de sintaxes espaciais: são práticas de espaço.

Esse raciocínio nos indica que a geografia imaginativa que inventa o Brasil não está localizada nalgum lugar dis-

\footnotetext{
${ }^{2}$ Utilizarei, alternada e aleatoriamente, tanto a forma abreviada (Deus e o Diabo) como a completa para identificar o filme de Glauber Rocha. Por questões de estilo e praticidade, irei me referir, daqui por diante, a Glauber Rocha simplesmente por Glauber.
} 
tante das narrativas, e que procurar entendê-la conduz ao inevitável encontro com as formas de narrar. Compreender a nação e suas configurações espaciais significa, se acompanharmos as idéias de Certeau, perscrutar as estratégias textuais utilizadas para contar suas histórias, e apreender os tropos que constituem essas narrativas.

Tropo significa volta, forma, maneira; o termo turn, mais especificamente, foi utilizado por muito tempo como sinônimo de tropo. Essa vinculação indica a proximidade entre as dimensões e variações espaciais e a construção das narrativas, relacionando diretamente estilo e espaço, maneira de contar e lugar. Nas línguas indo-européias o termo tropus remete a metáforas ou a figuras retóricas ${ }^{3}$. A análise tropológica, segundo Hayden White (1992 e 1994), nos permite aproximar das estratégias textuais características dos discursos, já que o conhecimento dos tropos possibilita ao pesquisador alçar as "formas estruturais profundas" da imaginação histórica. Os tropos não só refletem algo que existe antecipadamente, suas funções são, ao mesmo tempo, miméticas e performáticas: refletem e produzem no próprio ato enun-

\footnotetext{
${ }^{3}$ Para Hayden White, a noção de tropo dever ser vinculada à de estilo. Trata-se de conceito particularmente apropriado para o exame do discurso que, por sua vez, é percebido como gênero em que "predomina o esforço para adquirir este direito de expressão, com crença na total probabilidade de que as coisas possam ser expressas de outro modo" (1994, p. 15). White estuda a estrutura poética que caracteriza a imaginação histórica. Ao contrário de outros intérpretes, ele não supõe que a subestrutura "meta-histórica" dos clássicos consista nos conceitos teóricos utilizados. Os conceitos encontram-se na "superfície" do texto e podem ser facilmente detectados. É necessário captar e compreender o estilo historiográfico de cada autor, verificando as estratégias utilizadas por cada historiador para dar uma "impressão explicativa". A combinação específica dessas estratégias denominase estilo. Para correlacionar diferentes estilos como elementos de uma única tradição histórica, White foi levado a conceber um "nível profundo de consciência histórica", no qual o pensador escolhe os meios para explicar ou representar seus dados. Segundo ele, existem quatro modos principais de consciência histórica: metáfora, metonímia, sinédoque e ironia. O historiador, para imaginar "o que realmente aconteceu", deve prefigurar como objeto de conhecimento um conjunto de eventos. Esse ato prefigurativo é essencialmente poético. No ato poético, que precede a análise formal, o historiador cria seu objeto de análise e predetermina a modalidade de estratégias explicativas.
} 
ciativo ${ }^{4}$. Assim, concentrar a análise no ato poético possibilita alcançar essas narrativas performáticas que, por meio de noções de espaço, do exercício de uma geografia imaginativa, inventaram um Brasil.

As obras de Erich Auerbach (1987) e de E. H. Gombrich (1988) indagam quais os componentes "históricos" da arte realista, já a de White questiona quais são os elementos "artísticos" da historiografia "realista". Seria interessante embaralhar ainda mais as percepções de "realidade" e "ficção", ou de arte, história e realidade, e perguntar quais os elementos poéticos de determinadas narrativas ficcionais que contam certas histórias da nação.

Como se sabe, a literatura e o cinema se constituíram nos principais meios de expressão na edificação dos alicerces simbólicos da formação nacional. A literatura se estabeleceu como um dos primeiros pilares, sob o qual foram criados símbolos que representavam a identidade nacional, e se 14 transformou em instrumento de investigação e fenômeno central da vida intelectual do país. Assim como a literatura, o cinema também buscou interpretar o Brasil, pesquisando sobre a vida e sobre os problemas brasileiros. Enfim, a ficção, de uma forma geral, se preocupou em conhecer e transformar - construir, edificar - a nação. Por período considerável da história do país, as melhores expressões do pensamento nacional assumiram a forma ficcional. A investigação e a reflexão sobre o Brasil se iniciaram com a literatura e com o cinema, e só com a institucionalização das ciências sociais os papéis do romancista, do cineasta e do sociólogo começaram a se diferenciar, cedendo lugar à divisão de trabalho intelectual dos dias de hoje. Escritores e cineastas compreendiam o exercício de seus ofícios como missão, em que a arte só se realizava plenamente com presença da cor

\footnotetext{
${ }^{4}$ Judith Butler (1997) desenvolve essa análise em sua obra sobre a vida psíquica do poder.
} 
local e com atitude posicionada diante dos dilemas da nação. $\mathrm{Na}$ busca de um representante para o ideal brasileiro, a literatura e o cinema acionaram uma noção espacial específica - e que se tornou predominante na geografia imaginativa do país - para carregar sobre si o símbolo da identidade nacional: o sertã $o^{5}$.

Tanto na literatura como no cinema, a geografia imaginativa primou pela proeminência das narrações que destacavam as dimensões espaciais como aquelas que revelariam o mais genuinamente nacional. As narrativas edificaram poderosas imagens de um país construído pelo espaço; as dimensões de espaço e de territorialidade forjadas por essas imagens se constituíram num dos principais fundamentos do projeto da nação. Encantados com a imensidão territorial do país ou atormentados pela existência de gigantescos vazios, a imaginação social se voltou para o sertão que, ora como problema a ser resolvido, ora como índice da brasilidade, era conclamado a descrever a história da nação.

O sertão se transformou, então, na categoria central no processo de invenção do Brasil $^{6}$. Em algumas dessas narrativas, o sertão se configurou no signo da nação inacabada. A busca de uma homogeneização territorial se deparou com a necessidade de preencher os vazios - compreendida como condição da unidade nacional. Essa necessidade de preenchimento ressalta o imperativo da representação horizontal do espaço - que deve ser entendida como devenir na direção da homogeneização e unificação do território nacional.

\footnotetext{
${ }^{5}$ A importância da literatura no contexto brasileiro foi analisada por Antonio Candido (1976). Sobre a relação entre o cinema na descrição do Brasil, principalmente abordando a relação entre rural e a cidade, sertão e cidade, ver Jean Claude Bernardet (1980) e Célia Aparecida Ferreira Tolentino (2001). Sobre "missão", ver Nicolau Sevcenko (1983).

${ }^{6}$ Diversos autores analisaram o sertão, entre eles se destacam Lúcia Lippi de Oliveira (1993; 2000, especialmente o capítulo III), Janaína Amado (1995a e 1995b), Marcos Schettino (1995), Candice Vidal (1997), Sidney Valadares Pimentel (1997), Mireya Suárez (1998), Albertina Vincentini (1998), Gilmar Arruda (2000).
} 
O sertão se apresentava, nessa perspectiva, signo da cisão espacial e materializava a divisão da nação; sua existência pressupunha, portanto, um tempo disjuntivo, e justificava, na concepção desses inventores do Brasil, a própria empreitada pedagógica civilizatória das narrações. Ensejando imagens de vazio, de deserto, o sertão se colocava ora como obstáculo à homogeneização territorial e à eliminação das temporalidades disjuntivas, ora se creditava a ele a identidade nacional. De qualquer maneira, mesmo reconhecendo no sertão o cerne da brasilidade - aquilo que, nesse raciocínio, seria o mais genuíno, pois intocado pelos ares europeus ou norte-americanos -, a sua permanência se devia a uma imaginação civilizadora, preocupada com a alteridade dentro da nação.

É dessa busca de narrar a nação por meio da noção de espaço, tendo o sertão como modo de falar o Brasil, que surge um dos filmes mais importantes da cinematografia nacio16 nal, Deus e o Diabo na terra do sol, de Glauber Rocha. Essa película se destacou na considerável filmografia que aborda as relações entre sertão e nação, podendo ser considerada como uma das que mais bem explorou a geografia imaginativa da nação, por diversos fatores: pelo grau de influência no país, inspirando diversos cineastas; pela importância no quadro da ficção brasileira, já que o filme foi considerado por muitos o "ápice do cinema nacional”, colocando - com outras películas, como Os fuzis, de Ruy Guerra, e Vidas Secas, de Nelson Pereira dos Santos - o então denominado Cinema Novo no centro das polêmicas; e, para a análise que estou desenvolvendo, principalmente por sua singularidade de narrar - ou seja, por sua configuração tropológica. Singularidade que surge de uma configuração específica de relações entre espaço e narrativa, geografia imaginativa e tropo, "ficção" e "realidade". Daí a importância e a centralidade da alegoria em Deus e o Diabo, já que a alegoria, entendida como metáfora continuada, remete duplamente às dimen- 
sões de movimento e deslize, embaralhando movimento, espaço e tempo, configurando-se em noção privilegiada para compreender o filme de Glauber ${ }^{7}$.

Dentro deste contexto, podemos indagar: como se estrutura alegoricamente a obra de Glauber? Quais as imagens predominantes nas alegorias e de que maneira essas imagens inventam a nação? Tentarei argumentar a seguir - sem a intenção de exaurir o assunto e mais com o intuito de pontuar alguns dilemas enfrentados por Glauber - que essas questões podem indicar como uma noção de espaço nos fala sobre formas de lidar com a alteridade dentro da nação.

\section{A nação e seus outros}

A diferença do Brasil em relação aos outros foi reiteradamente colocada por diversos intelectuais, tornando-se mesmo um discurso recorrente entre os que, de várias formas e pelos mais variados meios, discutiam a nação. Seja se posicionando diante da tradição ocidental, seja lidando com a incômoda presença de outros na nação, as discrepâncias foram se acentuando nas formas de definir e delimitar o que era o Brasil, e na maneira de abordar as irredutíveis presenças de outros que destoavam dos ideais de homogeneidade da "comunidade imaginada" 8 . A complicada relação entre a tradição denominada de ocidental e o dado

\footnotetext{
${ }^{7}$ Na definicão clássica de Lausberg (citada em Hansen, 1986), a "alegoria é a metáfora continuada como tropo de pensamento, e consiste na substituição do pensamento em causa por outro pensamento, que está ligado, numa relação de semelhança, a esse mesmo pensamento". A alegoria, assim como o tropo, é uma transposição de sentidos, porém, diferentemente dos tropos, as alegorias devem apresentar movimento. É neste sentido que Hansen (1986, p. 14) dirá que a "alegoria é um tropo de salto contínuo". Sobre alegoria, ver ainda o texto de Ismail Xavier (2004).

${ }^{8} \mathrm{O}$ conceito de comunidade imaginada foi elaborado por Benedict Anderson (1989). Para acompanhar a rica discussão sobre a nação, ver, entre outros, Homi Bhabha (1990 e 1998), Stuart Hall (1997), Stuart Hall e Paul Du Gay (1997), Partha Chatterjee (2000), Rita Laura Segato (2007).
} 
local gerou, então, rica literatura e debates acalorados por toda história do país. A dúvida sobre as peculiaridades da brasilidade assombrou os intelectuais, sejam romancistas, poetas, ensaístas, cineastas.

A escolha de um modo de se falar a nação dependeu sempre da tomada de um ponto para discorrer. A opção de qual nação se deve representar invadiu os anseios dos inventores do Brasil, anseios que geraram profusão de temas que vão desde os índios, passando pelo cangaço, pampas, alcançando as favelas e as singulares formas de urbanização. Como já se argumentou, parte significativa das narrativas se concentrou em nossas categorias espaciais quando procurou definir a singularidade do Brasil. O sertão surgiu dessa vontade de falar a nação pelo espaço e se constituiu, vale repetir, numa das formas mais importantes por meio da qual o país foi inventado. Nesse quadro geral, Deus $e o$ Diabo apresenta, simultaneamente, forma diferenciada de 18 se relacionar com a herança ocidental e nova maneira de falar sobre o sertão.

O filme absorve e transforma o legado do cinema ocidental e da tradição cinematográfica em geral. A intenção é a de liberar a linguagem cinematográfica do mimetismo das formas clássicas do cinema internacional, sobretudo do cinema europeu e norte-americano. Glauber reinventa as tradições literárias ou cinematográficas, buscando transformá-las. Podem-se detectar as influências e a tentativa de superá-las observando as citações expressas neste filme. Cinematograficamente, identificam-se: Rosselini, Kurosawa, Eisenstein, Visconti; teatralmente: os trágicos gregos e Brecht; literariamente: James Joyce, Euclides da Cunha, José Lins do Rego e, fundamentalmente, Guimarães Rosa. Até Wagner - e sua teoria da ópera como "obra de arte total" (Gesamtkunstwerk) - poderia ser lembrado. O movimento de Glauber é duplo. As experiências devem ser traduzidas, num complexo processo de deslocamento e reconfiguração. 
E justamente por esse processo de tradução - que nunca é perfeito - o resultado é um cinema impuro - a hipótese aventada por André Bazin (1991) tomando forma nas películas de Glauber. Trata-se, pois, de um cinema híbrido.

Glauber utilizará as influências recebidas de Eisenstein, Renoir, Resnais, John Ford, Visconti, Godard, mas fazendolhes uma inversão. Da mesma forma que Guimarães Rosa procurou fazer uso da influência de James Joyce - entre numerosos outros autores - para evidenciar e reinventar a fala sertaneja, Glauber vale-se da herança internacional no intuito de edificar uma linguagem específica para o seu cinema. A narrativa absorve, mas transforma; mimetiza, mas trai. O movimento feito por Glauber, portanto, se assemelha à reinvenção da língua por Guimarães, fato que por si já sinaliza a íntima relação entre essas obras. Se, como argumenta Willi Bolle (2004), Grande sertão veredas reescreve Os sertões, de Euclides da Cunha, Deus e o Diabo perfaz uma releitura de uma releitura, camada sobre camada, construindo, numa teia intertextual, o sertão - teia que desestabiliza a linguagem, propiciando nova forma de narrar.

Tal questão pode ser visualizada numa passagem do filme bastante comentada pelos críticos. Trata-se da citação da famosa cena da "Escadaria de Odessa" de O Encouraçado Potenkim, de Sergei Eisenstein. Glauber realiza nova leitura, pois a montagem de Odessa é racional, equilibrada, evolutiva e matemática; em Deus e o Diabo a montagem é fora de ordem, fora da continuidade, anárquica. Na tradução efetuada ocorre um deslize que, ao mesmo tempo em que cita, se afasta daquilo que evoca. Nessa pequena passagem podemos observar como uma exposição evolutiva das imagens se choca com uma linguagem fragmentada, despedaçada.

O movimento de evitar uma linguagem demasiadamente colada à tradição do cinema ocidental se deve, em grande parte, à busca de Glauber de se distanciar de uma perspectiva que tematizava o outro sertanejo sempre sob o prisma da 
cidade, ou seja, sempre por um olhar civilizado e civilizador exercido sobre um outro ignoto. Esse movimento de trazer o outro sem domesticá-lo em moldes pré-concebidos por um olhar externo também proporciona desestabilização na linguagem, que mencionei acima, e permite se aproximar do sertão por dentro. O cotejamento de $O$ cangaceiro, de Lima Barreto, e Deus e o Diabo, pode tornar mais claro o que significa essa desestabilização que possibilita falar o sertão por dentro.

As duas obras abordam o sertão e o cangaço. O cangaceiro tem intenção de conferir alto grau de verossimilhança, no objetivo de retratar o sertanejo "de verdade"; o filme se estrutura numa composição que se limita aos moldes da decupagem clássica; na película de Lima Barreto, os temas nacionais são, assim, exaltados por linguagem tributária aos moldes europeus e norte-americanos.

Existe em $O$ cangaceiro uma distância que separa o narrador de seu objeto. O narrador "organiza tudo em função de 20 um único olhar, centralizador, que dispõe as figuras com muito cuidado no momento de fazê-las posar diante da objetiva”, nos diz Ismail Xavier (1983, p. 133). A distância ensejada no próprio ato de descrever coloca o sertanejo como um Outro, separando-o do Eu civilizado. O sertanejo é enquadrado como primitivo e localizado no passado, ao narrador civilizado cabendo a tarefa de tratá-lo como objeto a ser estudado e domesticado. O cangaceiro propõe, portanto, raízes para a nacionalidade, acentuando que essas raízes deveriam ser domesticadas, civilizadas. O sertão é o Brasil por enquanto e necessita ser domesticado pela civilização; nos "dois brasis" um deve ceder e deixar espaço ao civilizado 9. Enfim, os procedimentos narrativos impõem uma inextinguível distância entre os brasis.

\footnotetext{
${ }_{9}$ Paulo Emílio Sales Gomes (1986), ao analisar o mito da "obra prima perdida", de Lima Barreto, que teria o nome significativo de $O$ sertanejo, diz parecer ser impossível que Lima Barreto declarasse qualquer manifestação de adesão afetiva aos valores arcaicos de um país agrário e pouco desenvolvido.
} 
Deus e o Diabo busca suprimir essa distância que caracteriza $O$ cangaceiro, por meio de diversos procedimentos narrativos: elimina-se o narrador centralizador, a utilização de músicas, do cordel, de vozes populares - do cego Júlio, por exemplo - conduz à polifonia, que descentraliza a narração. Há, enfim, a exploração intensiva da diversidade de vozes e da variedade de tipos de discurso. O filme de Lima Barreto olha o sertanejo e o sertão a partir de uma distância denunciada pela própria narrativa, apesar da tentativa de lhe prestar homenagem; o de Glauber procura eliminar essa distância, principalmente acentuando o caráter intertextual, emaranhando os desenredos e intertextos - procedimento que evita a redução etnocêntrica que vê no sertão e no sertanejo figuras de pensamento irracional ${ }^{10}$.

As características de Deus e o Diabo alinhavadas até aqui nos levam a concluir, então, que Glauber filmou no epicentro das contradições entre a afirmação do Brasil diante de um outro externo e a presença de outros na nação, a

\footnotetext{
${ }^{10}$ Para uma análise dos termos desenredo e intertexto, numa comparação de Grande Sertão: veredas e Deus e o Diabo na Terra do Sol, ver Pereira (2007). Podemos lembrar aqui também, e somente para nuançar em Glauber a tentativa de evitar uma fala de fora do sertão, de Vidas Secas, de Graciliano Ramos, referência das mais importantes da literatura nacional. Livro utilizado nas escolas de primeiro e segundo graus e nos cursos pré-vestibulares e que nos surge à memória quando falamos em sertão. Na prosa direta de Graciliano surge a expressão da carência, da miséria, do mutismo, da exclusão. O sertão aparece como espaço distante, sendo expressão metonímica do isolamento e do silêncio, e sinédoque da exclusão. Em Graciliano existe a tentativa de se aproximar do pensamento do sertanejo. O narrador fala dos desejos de Fabiano - personagem central da narrativa - assinala-os, ressalta-os. Mas há também uma distância entre narrador e o sertanejo. Graciliano simpatiza com os "oprimidos", mas observa na sua voz a inconsciência, construindo e ressaltando a diferença entre o narrador e as personagens. Num determinado momento, por exemplo, Fabiano voltava de uma operação de cura, percorrendo a beira do rio, agitando os braços para direita e para esquerda. Graciliano interpreta os gestos do vaqueiro como "inúteis". A inutilidade foi proclamada por um narrador que, sabendo-se distante, pode compreender com segurança as idéias do vaqueiro. O saber coloca o autor como homem da cidade, que se percebe com idéias corretas que devem ser manifestas. Nada mais distante do narrador do que as curas realizadas por Fabiano; assim, os elementos simbólicos religiosos assinalam e nuançam o apartamento entre narrador e sertanejo.
} 
presença de uma pluralidade de vozes e sujeitos históricos diante da vontade unitária e de empreendimentos de um Estado Nacional que planifica a diversidade interior ${ }^{11}$. Se Deus e o Diabo deve ser compreendido dentro dessa tensa relação com os outros interiores e exteriores - no contexto de uma nação que produz no mesmo movimento o perfil da estrutura assimétrica de sua alteridade interior e a natureza das suas relações com os outros exteriores - e se Glauber busca, simultaneamente, falar o sertão por dentro e construir um cinema nacional, devemos, para continuar a desenvolver o raciocínio, insistir em compreender as outras histórias que as suas alegorias nos contam ${ }^{12}$.

\section{Alegorias em Deus e o Diabo na terra do sol}

Glauber evoca momentos importantes da história do Brasil, mas, por todo o filme, procede de maneira a se afastar de um realismo factual que esteve presente em certa filmo22 grafia nacional. Ele abstrai situações e personagens de sua concretude imediata; busca no cordel estrutura simultanea-

\footnotetext{
${ }^{11}$ Todo Estado nacional vale-se da instalação de seus outros para se entronizar, como adverte Rita Laura Segato (2007, p. 138), existindo um processo vertical de gestação da unidade, do conjunto e o isolamento de identidades - consideradas residuais ou periféricas da nação. Ao mesmo tempo em que se comporta como "positividade histórica" a nação produz os seus outros (Segato, 2007, p. 184). Cada história nacional particular produz uma matriz, e essa configuração histórica afetando as próprias narrativas. Na composição do subtítulo A nação e seus outros, valho-me diretamente do livro de Segato (2007).

${ }^{12}$ Fredrich Jameson (1982) vem afirmando que a alegoria nacional é a forma principal - ou exclusiva - de narratividade do terceiro mundo. Críticas recentes, como as de Aijaz Ahmad (2002), têm apontado o caráter homogeneizante da formulação de Jameson, já que ele acaba por construir um "terceiro mundo" como alteridade total, e a enorme heterogeneidade se subsume numa experiência singular. A discussão das alegorias em Deus e o Diabo apresentam outras dimensões deste debate. $\mathrm{O}$ cinema de Glauber se expressa por alegorias; mas, são alegorias que desenham fissuras, diferenças, contradições, alegorias do dilaceramento da nação. Dessa forma, perceber as alegorias somente como construções imagéticas (por exemplo) que unificam um todo nacional, sempre pensado em contraposição às nações centrais, tal como propõe Jameson, se constitui num movimento que - para além das críticas de Ahmad e mesmo considerando a existência e os dilemas das narrativas alegóricas e a nação - se olvida da formação dos outros na nação.
} 
mente real e fantástica - ele, na verdade, elimina essa distinção entre o real e o fantástico; dramatiza as ações, retirando-lhes o caráter cotidiano.

As seqüências do filme expressam íntima conexão entre abstração e reflexão, elaborando, por meio dessa forma de narrar, uma síntese das dramatizações de eventos históricos importantes na história do país. Fatos e seres pertencentes à história são reinventados, as ações são encenadas, o comportamento das personagens extrapola as atitudes cotidianas, a música e as danças contribuem para sair do caráter convencional. A estrutura fílmica, portanto, prima pela busca, incessante e sempre inconclusa, de desconstruir qualquer vinculação direta e sem mediação a algum fato histórico específico.

A estrutura narrativa parece afirmar que o factual não importa em primeira instância. Utiliza-se, por exemplo, A canção do sertão e Chorus $n^{\circ} 10$, de Villa-Lobos, para introduzir e finalizar a obra. A seqüência em que Antônio das Mortes aparece atirando e matando cangaceiros é acompanhada pela câmara na mão e pela música Mindinho (dança das Bachianas brasileiras $n^{\circ} 4$ ). A canção de Sérgio Ricardo, com letra de Glauber, narra a história, assemelhando-se aos coros das tragédias gregas. A linguagem opera, dessa maneira, no sentido de acentuar a dramaticidade das cenas, produzindo o efeito de irrealidade.

Ocorrem alterações nas estruturas do espaço e do tempo. A história se desenrola acronologicamente, como demonstra a cena em que Antônio das Mortes mata os beatos e aparece em vários lugares ao mesmo tempo; noutra parte do filme, Corisco grita e salta para os lados, numa atitude inverossímil. A organização das imagens, portanto, procura sair do naturalismo e das atitudes convencionais, direcionando-se às ações dramatizadas, que se estendem por toda a película. Outra seqüência exemplar é a da penitência de Manuel que carrega, ajoelhado, uma pedra pelo 
caminho de Monte Santo. A câmara acompanha cada movimento e, ao mesmo tempo, oferece imagens da escadaria. O resultado é duplo: podemos acompanhar a dimensão do empenho de Manuel e, ao captar tal esforço, a câmera produz a intensidade da situação.

A câmera, em diversas partes da película, acentua cada passo da dramatização: fixa e imóvel, quando as situações que exprime requerem a lentidão dos movimentos; ágil, quando as circunstâncias são de mobilidade - como nas seqüências de Monte Santo nas quais Glauber utiliza a câmara na mão para as cenas em que Rosa vaga pela multidão, e a câmara fixa, para as cenas do interior da capela.

A montagem do filme se recusa à exibição de sucessão de gestos contínuos e racionalmente situados, como nos lembra Ismail Xavier (1983, p. 70). Glauber utiliza o processo de condensação. Parte de realidade múltipla, retirando o material para o seu texto, com o objetivo de estabele24 cer imagens simultaneamente precisas e gerais, abstratas e específicas. Quando, por exemplo, vemos as personagens Antônio das Mortes, Santo Sebastião, Corisco ou Manuel, o que surge na tela extrapola a singularidade das figuras históricas, já que condensam diversos personagens de vários movimentos socioculturais no Brasil. No filme, para exemplificar o procedimento de Glauber, Corisco é, ao mesmo tempo, um personagem histórico e representa todos os cangaceiros, além da referência imediata e significativa ao próprio Lampião. Trata-se, portanto, de metáforas históricas: alegorias do Brasil.

Deus e o Diabo evoca Canudos, Juazeiro e Padre Cícero, Virgulino Lampião, Corisco, Caldeirão, Sebastião e o sebastianismo, interpretando lugares, personagens e situações importantes da história do Brasil. A evocação dá-se por meio de metáforas. Quando Santo Sebastião aparece na tela, apresenta-se a relação de semelhança e diferença com Antônio Conselheiro, Beato Lourenço do Caldeirão e 
vários outros líderes messiânicos. As metáforas identificam as personagens e proporcionam o deslocar da realidade empírico-concreta. São metáforas continuadas, imagens alegóricas que perpassam e contam uma história do País. As metáforas ultrapassam significantes concretos, colocando-se num continuum. As alegorias do filme excedem a correlação entre sentido literal e sentido figurado, e apresentam complexa conexão entre designação concretizante e as outras figurações, abstrações e associações.

Antônio das Mortes é relacionado ao coronel José Rufino, matador de Lampião, e representa, ao mesmo tempo, todos os matadores de cangaceiros. Corisco, para continuar com o exemplo já citado, possuído por Lampião, em transe, fala, alternadamente, com as suas palavras e as de Lampião. A relação, que de início aparenta ser metonímica - Corisco, figura histórico-concreta -, na realidade é metafórica: ele representa as qualidades dos cangaceiros do sertão.

A morte de Corisco e de Lampião, os episódios de Pedra Bonita e de Canudos, a própria figura do matador de cangaceiros Antônio das Mortes, condensam situações e personagens. O massacre dos beatos na escadaria de Monte Santo metaforiza a chacina de Canudos; o sacrifício de uma criança, empreendido por Santo Sebastião e Manuel, vincula-se aos episódios de Pedra Bonita; Antônio das Mortes metaforiza Coronel José Rufino; e assim por diante.

No processo de dramatização de determinados momentos históricos do país, o filme reinventa a realidade, urdindo tempo, espaço, biografia e geografia, sempre em novas configurações imaginativas, e possibilitando visão alternativa dos personagens e dos episódios. Narrando uma história do Brasil, a película não se contenta em apresentar o real, ou identificar "personagens reais"; antes, prefere (re)criálos alegoricamente. Glauber elabora - continuando a exemplificar as formas de construções alegóricas em Deus e o Dia$b o$ - imagem do cangaceiro que, ao mesmo tempo em que 
o apresenta como tipo, projeta-o para fora do tempo (cf. Xavier, 1983). A alegoria capta e produz a complexidade das relações entre figura histórico-concreta e personagem alegórica. Da mesma forma, Beato Sebastião está além da figura empírica de Antônio Conselheiro. Os personagens contam casos, propõem lições, e as alegorias contam-nos, assim, outras histórias. Podemos, aqui, nos fazer a seguinte pergunta: se alegoria significa dizer alguma coisa por meio de outras, quais imagens dessa(s) outra(s) história(s) que Glauber narra? O que significa, também, indagar: em Deus e o Diabo as alegorias seriam pedagógicas ou teriam o sentido de dilaceramento das alegorias modernas?

\section{Dilaceramento}

Algumas narrativas construíram o sertão como lugar distante, agreste, difícil, pobre, não civilizado, estabelecendo-o como aquilo que deveria ser vencido e domesticado para o êxito 26 da nação. Outras edificaram o sertão como o arcaico idealizado, ressaltando características que sugerem as peculiaridades da identidade nacional - identidade esta intocada e petrificada, e sempre vista sob o prisma civilizador. O sertão seria contraponto ideal, aquele que revelaria a contrapelo o presente-civilizado. Nas duas alternativas, a idéia de nação se institui como algo teleológico, e previamente determinado, o sertão se constituindo, replicando aqui, de forma diferenciada, o argumento de Partha Chatterjee (2000), num eterno "consumidor da modernidade".

Não é difícil encontrar essa forma de configurar o sertão mesmo em comentadores da obra de Glauber. Trata-se, nesse caso, de se atribuir a Deus e o Diabo o que se estabelece como ideal da nação, expressão que deve ser compreendida tanto no sentido de imaginação da nação, como no sentido de busca, desejo e construção de um tipo nação. O ideal de nação é uma projeção que deve ser percebida dentro de um contexto determinado. A gestação dos Estados Nacio- 
nais modernos, os princípios de civilidade, a pacificação das relações dentro do Estado e as formas racionais de controlar as diferenças e as relações sociais formam um conjunto que se imprime como ideal de boa sociedade.

É o ideal de nação e a pressuposição da modernidade-civilidade como meta que conduz às imagens do sertão como algo a ser vencido, ou do sertão arcaico, idealizado, petrificado numa distância tranqüilizadora. Esse ideal de nação pode permitir, por exemplo, enquadrar Deus e o Diabo no universo das obras que construíam o processo civilizatório da nação, que dissertavam sobre a eliminação da violência e advogavam a necessidade de um controle centralizado. $\mathrm{O}$ cinema de Glauber seria, nessa perspectiva, uma manifestação ficcional da luta para transpor obstáculos na tentativa de conter e superar a violência, e Deus e o Diabo narraria a assimilação das regras de vida social e novos costumes políticos, com vistas à instituição no país de uma civilização; o sertão-Brasil seria construído alegoricamente como espaço em que predominavam as relações arcaicas, mas que experienciava as possibilidades de civilização.

Numa direção oposta, como se depreende dos argumentos até aqui expostos, na minha leitura as alegorias em Glauber nos apresentam imagens de uma nação dilacerada, tratando-se, sobretudo, de uma narrativa que nos conta outras histórias em que o sertão é evocado para, a partir da dissidência e das margens, falar à nação. Assim, se a identidade é perseguida, o efeito se dá pela diferença, por meio de alegorias que inventam um Brasil clamando as margens - cangaceiros, jagunços, sertanejos despossuídos - para contar uma outra história, a despeito do projeto hegemônico de nação.

O sertão de Glauber é o local de conflito de temporalidades diversas, superpostas, sítio do confronto de culturas ${ }^{13}$.

\footnotetext{
${ }^{13}$ Nesse aspecto, Glauber se aproxima de Guimarães Rosa, como pode ser observado na interpretação de Marli Fantini (2003, p. 83). A obra de referência para Deus e o Diabo é, sem dúvida, Grande sertão: veredas. A construção alegórica nos indica as
} 
Nesse espaço, a idéia de nação como temporalidade única, como parte de um processo unidirecional e civilizatório que vai abarcar o sertão, perde o sentido, e o sertão emerge como espaço alternativo a questionar a naturalização: a) do território, já que sertão e mar se confundem e que o sertão está em toda parte e em parte alguma; b) da língua, já que se reinventa a linguagem e se mesclam falas populares e eruditas, e que a tradição cinematográfica internacional é relida, traduzida, numa linguagem que se aproxima da dos mitos; c) do tempo, já que temporalidades diferenciadas são alocadas lado a lado. Deus e o Diabo questiona, assim, a própria naturalidade da nação.

Podemos, aqui, lembrar a releitura de Glauber sobre a visão de Euclides da Cunha (1985) da história de Canudos. Em Os sertões existe um duplo movimento no qual certo cientificismo - ou uma linguagem que se quer e se constrói como descritiva, objetiva e científica - que estabelece dis28 tância, inclusive com manifesto preconceito, entre Canudos e República, Canudos e a Civilização, ou ainda, entre sertão e litoral, se vê invadido por uma narrativa épica que estiliza os "jagunços" como heróis, idealizados e também cuidadosamente mantidos numa distância temporal que se almeja extinguir. É com esse raciocínio que Willi Bolle concluirá que "Euclides acaba legitimando - mais uma vez e definitivamente - o aniquilamento de Canudos" (2004, p. 38). Como vimos, o movimento de Glauber é justamente o de buscar

relações de proximidade existentes entre o romancista e o cineasta. Guimarães nos apresenta figuras e eventos históricos, geografia e datas, alegoricamente. O romance espalha fragmentos da história nacional, conforme nos alerta Bolle (2004), inserindo expressões como: "missionário esperto engambelando os índios", "pretos que bateavam em faisqueiras", "capitão da Guarda Nacional", "no tempo do Bom Imperador". Também em Guimarães, o sistema jagunço, o coronelismo, a plebe rural, Canudos, Antônio Conselheiro, se distanciam de suas manifestações sócio-históricas imediatas e se tornam alegorias que falam e interpretam as estruturas do país. Na verdade, Deus o Diabo se configura numa reescrita de Grande sertão: veredas, a forma alegórica de narrar a nação sendo, portanto, comum aos dois autores. 
eliminar essas distâncias e de falar o sertão por dentro. $\mathrm{O}$ cineasta retira Canudos de sua existência factual empírica, convertendo-o em alegoria, e como alegoria Canudos passa a representar as lutas das comunidades autônomas que desafiaram as relações de poder em diferentes momentos da história, abarcando e ressaltando, assim, todos os movimentos messiânicos do Brasil. A construção alegórica possibilita, dessa forma, dar maior complexidade às revoltas e às formas de resistências (ver Gatti, 1995; Xavier, 1983, p. 118; Tolentino, 2006). A reinvenção do Brasil ocorre, então, por meio de alegorias que dão maior complexidade à reflexão sobre o sentido das revoltas camponesas, sobre o messianismo, o cangaço, os jagunços e a religiosidade popular. As alegorias colocam os eventos numa era imaginária, fora de definições convencionais do espaço e do tempo, e é esse outro tempo que resiste e se coloca como diferença na construção da nação. Temos em Glauber, portanto, uma leitura que se opõe diretamente à de Euclides da Cunha.

Dar maior complexidade à construção alegórica, contudo, implica riscos, pois narrar outra história significa escolher, ressaltar, delimitar, num processo de edificação que nunca se controla completamente. E aquilo que resta, fruto de uma narrativa pressionada por todos os lados - pressionada por uma tradição cinematográfica que se necessita traduzir, por expressões eruditas e populares que resistem à tradução - faz com que o contar outra história seja sempre outra história e, assim, a idéia de um cineasta totalmente consciente dos processos de fabricação de sua arte, ora desenhando o sertão em cores marxistas, ora destilando uma ideologia desenvolvimentista, fazendo o mar coincidir com a revolução, e a revolução coincidir com a revolução socialista, olvida justamente os riscos e a imprevisibilidade das construções alegóricas.

Ao contrário de alegorias pedagógicas e previsíveis, essas outras histórias de uma narrativa pressionada, fruto de tensa relação com os outros interiores e exteriores, nos apresen- 
tam um sertão dilacerado, eivado de personagens inseguros, seres desolados, ambíguos, e em constante travessia. Daí, por exemplo, Ismail Xavier (1983, p. 119), que elaborou um dos trabalhos mais relevantes sobre Glauber, constatar, como conclusão da seção que analisa Deus e o Diabo, no livro Sertão Mar, como a alegoria pedagógica - ele utiliza a expressão "didática" - "se vê invadida pela alegoria no sentido moderno, figura do dilaceramento".

Na concepção de Walter Benjamin, alegoria é, simultaneamente, ruína e fragmento; e forma de contar algo sobre a degradação e opressão, o que permite o surgimento de uma história inconclusa e em permanente transformação. O ponto central da visão alegórica consiste na exposição barroca da história como história do sofrimento, valendose de imagens da ruína como fragmento significativo, cujos elementos não se unificam num todo integrado. O tempo surge como natureza em ruína. O sofrimento humano e a 30 ruína são, pois, matéria e forma da experiência histórica ${ }^{14}$.

As alegorias em Glauber se centram na nação dilacerada; o sertão se constituindo no lugar de ruína e sofrimento. O dilaceramento se manifesta na linguagem cinematográfica, na maneira despedaçada de narrar; na própria violência das imagens, que as cenas na escadaria expressam tão bem; nas histórias despedaçadas de personagens despossuídos, como Manuel e Rosa, mas também como Corisco, de Antônio das Mortes, de Santo Sebastião; na violência e na ambigüidade dos personagens em travessia; nos desentendimentos e conflitos que perpassam toda a película. As alegorias expressam, então, as disjunções, e rompem com a idéia de uma temporalidade única, na medida em que inscrevem na história da nação outros momentos, alertando para a violência contida na própria idéia de um tempo sincrôni-

\footnotetext{
${ }^{14}$ Ver Susan Buck-Morss (2002, p. 203). Para uma densa discussão de alegoria e história em Walter Benjamin, ver Olgária Matos (1989) e Willi Bolle (2004).
} 
co no qual o sertão ora deveria ser vencido pela civilização, ora seria petrificado como arcaico idealizado e superado. O procedimento alegorizante sugere, dessa forma, outros tempos, que deslizam e produzem uma identificação coletiva performativa que se distancia das tentativas de construção de uma identidade nacional transcendente e única. Os tropos assinalam e realçam as diferenças e as fraturas e, em denso diálogo com diversas tradições - sejam elas literárias ou cinematográficas, populares ou eruditas -, se distanciam de uma visão que essencializa e homogeneíza a nação.

\section{Pedro Paulo Gomes Pereira}

é doutor em Antropologia, Universidade de Brasília, e Professor do Programa de Pós-graduação em Ciências da Saúde/Unifesp

\section{Bibliografia}

AHMAD, A. 2002. Linhagens do presente. São Paulo: Boitempo Editorial. ANDERSON, B. 1989. Nação e consciência nacional. São Paulo: Ática.

AMADO, J. 1995a. "Construindo mitos: a conquista do oeste no Brasil e nos EUA”. In: PIMENTEL, S. V.; AMADO, J. (orgs.). Passando dos limites. Goiânia: Ed. UFG.

1995b. "Sertão, nação". Estudos Históricos, Rio de Janeiro, vol. $8, \mathrm{n}^{\circ} 15$.

ARRUDA, G. 2000. Cidade e sertões. Entre a história e a memória. Bauru, SP: Edusc.

AUERBACH, E. 1987. Mimesis. A representação da realidade na literatura ocidental. São Paulo: Perspectiva

BALAKRISHNAN, C.; ANDERSON, B. (orgs.). 2000. Um mapa da questão nacional. Rio de Janeiro: Contraponto.

BAZIN, A. 1991. O cinema. Rio de Janeiro: Brasiliense.

BENJAMIN, W. 1980a. "A obra de arte na época de suas técnicas de reprodução”. In: Os Pensadores. São Paulo: Abril. . 1980b. "O narrador". In: Os Pensadores. São Paulo: Abril. . 1984. Origem do drama barroco alemão. São Paulo: Brasiliense.

BERNARDET, J. C. 1980. "A cidade, o campo". In: Cinema brasileiro: estudos. Rio de Janeiro: Funarte. (org.). 1991. Glauber Rocha. São Paulo: Paz e Terra. 
BHABHA, H. K. 1990. "Dissemination: time, narrative, and margins of the modern nation”. In: Nation and narration. New York: Routledge. 1998. O local da cultura. Belo Horizonte: Ed. UFMG.

BUCK-MORSS, S. 2002. Dialética do olhar. Walter Benjamin e o projeto das passagens. Belo Horizonte: Ed. UFMG

BOLLE, W. 2004. grandesertão.br. São Paulo: Duas Cidades/Ed. 43.

BUTLER, J. 1997. The psychic life of power: theories in subjection. California: Stanford University Press.

CANDIDO, A. 1976. Literatura e sociedade. São Paulo: Companhia Editora Nacional.

CERTEAU, M. de. 1996. A invenção do cotidiano. Artes de fazer. Petrópolis, RJ: Vozes.

CHATTERJEE, P. 2000. "Comunidade imaginada por quem?" In: BALAKRISHINAN, G.; ANDERSON, B. (orgs.). Um mapa da questão nacional. Rio de Janeiro: Contraponto.

CLIFFORD, J. 1998. "Sobre a automodelagem etnográfica: Conrad e Malinowski”. In: A experiência etnográfica. Rio de Janeiro: Ed. UFRJ.

CUNHA, E. da. 1985. Os sertões: campanha de Canudos. São Paulo: Brasiliense.

GATTI, J. 1995. Dialogism and syncretism in the films of Glauber Rocha. Tese de doutorado. New York: Universidade de New York.

GOMBRICH, E. H. 1988. Arte e Ilusão: um estudo da psicologia da representação pictórica. São Paulo: Martins Fontes.

HALL, S. 1997. Identidades culturais na pós-modernidade. Rio de Janeiro: DP\&A.

; DU GAY, P. 1997. Questions of cultural identity. London: Sage.

HANSEN, J. A. 1986. Alegoria. Construção e interpretação da metáfora. São Paulo: Atual.

JAMESON, F. 1982. The political unconscious. Narrative as socially symbolic act. New York: Cornell University Press.

LIPPI DE OLIVEIRA, L. 1993. "Bandeirantes e pioneiros. As fronteiras no Brasil e nos Estados Unidos”. Novos Estudos Cebrap, São Paulo: Brasileira de Ciências.

2000. Americanos. Representações da identidade nacional no Brasil e nos EUA. Belo Horizonte: Ed. UFMG, vol. 37.

MATOS, O. 1989. Os arcanos do inteiramente outro. A Escola de Frankfurt, a melancolia e a revolução. São Paulo: Brasiliense.

PEREIRA, P. P. G. 2007. Sertão e narração: Guimarães Rosa, Glauber Rocha e seus desenredos. No prelo.

PIMENTEL, S. V. 1997. O chão é o limite. A festa do peão de boiadeiro e a 
domesticação do sertão. Goiânia: Ed. UFG.

; AMADO, J. (orgs.). 1995. Passando dos limites. Goiânia: Ed. UFG.

PONTES, N. B. 1965. "Aproximações literárias e criação crítica”. In: Glauber Rocha. Rio de Janeiro: Civilização Brasileira.

RAMOS, F. P. (org.). 2004. Teoria contemporânea do cinema. Pós-estruturalismo e filosofia analítica. São Paulo: Senac, vol. I.

RONCARI, L. 2004. O Brasil de Rosa. O amor e o poder. São Paulo: Ed. Unesp.

ROSA, J. G. 1986. Grande sertão: veredas. Rio de Janeiro: Nova Fronteira.

SCHENTTINO, M. P. F. 1995. Espaços do sertão. Dissertação de Mestrado. Brasília: DAN/UnB.

SALES GOMES, P. E. 1986. Paulo Emílio: um intelectual na linha de frente. Coletânea organizada por Carlos Augusto Calil e Maria Teresa Machado. Rio de Janeiro: Brasiliense.

SEGATO, R. L. 1995. Santos e daimones. O politeísmo afro-brasileiro e a tradição arquetipal. Brasília: Ed. UnB.

2007. La nación y sus otros. Raza, etnicidad y diversidad religiosa en tiempos de políticas de la identidad. Buenos Aires: Prometeo Libros.

STRATHERN, M. et al. 1996. Key debates in anthropology. Londres: Routledge.

TOLENTINO, C. A. F. 2001. O rural no cinema brasileiro. São Paulo: Ed. Unesp.

VICENTINI, A. 1998. "O sertão e a literatura”. Revista Sociedade e Cultura. Goiânia: Ed. UFG.

VIDAL, Candice. 1997. A pátria geográfica: sertão e litoral no pensamento social brasileiro. Goiânia: Ed. UFG.

VIVEIROS DE CASTRO, E. 2002a. "O nativo relativo”. Mana. Estudos de Antropologia Social, 8(1).

2002b. A inconstância da alma selvagem e outros ensaios de antropologia. São Paulo: Cosac Naify.

XAVIER, I. 1983. Sertão mar: Glauber Rocha e a estética da fome. São Paulo: Brasiliense.

2004. "A alegoria histórica". In: RAMOS, F. P. (orgs.).Teoria contemporânea do cinema. Pós-estruturalismo e filosofia analítica. São Paulo: Senac, vol. I.

WHITE, H. 1992. Meta história. A imaginação histórica do século XIX. São Paulo: Edusp.

. 1994. Trópicos do discurso. Ensaios sobre a crítica da cultura. São Paulo: Edusp. 


\section{Filmes citados}

O cangaceiro. 1953. Direção: Lima Barreto. Brasil.

Vidas secas. 1963. Direção: Nelson Pereira dos Santos. Brasil.

Os fuzis. 1964. Direção: Ruy Guerra. Brasil.

Deus e o Diabo na terra do sol. 1964. Direção: Glauber Rocha. Brasil. 


\section{O SERTÃO DILACERADO: OUTRAS HISTÓRIAS DE DEUS E 0 DIABO NA TERRA DO SOL}

PEDRO PAULO GOMES PEREIRA

A busca deste texto será a de compreender como uma das mais importantes narrativas do cinema nacional - Deus e o Diabo na terra do sol, de Glauber Rocha (1963) - construiu o sertão, quais as imagens e as figuras utilizadas, e como esse sertão delineia e projeta o Brasil.

Palavras-chave: Sertão; Nação; Cinema brasileiro.

\section{THE BRAZILIAN HINTERLAND IN GLAUBER ROCHA'S CINEMA}

This article tries to understand how one of the most important narratives of the national cinema - Glauber Rocha's Black God, white devil (1963) - has constructed the sertão (hinterland), which images and figures he has employed, and how that hinterland delineates and projects the country.

Keywords: The hinterland; Nation; Brazilian Cinema. 